\title{
Morfologia externa do adulto de Hemiargus hanno (Lepidoptera, Lycaenidae, Polyommatinae, Polyommatini). II. Região cervical, tórax e abdome
}

\author{
Marcelo Duarte \\ Museu de Zoologia, Universidade de São Paulo, Avenida Nazaré 481, Ipiranga, 04263-000 São Paulo, SP, Brasil. (mduartes@usp.br)
}

\begin{abstract}
External adult morphology of Hemiargus hanno (Lepidoptera, Lycaenidae, Polyommatinae, Polyommatini). II. Cervix, thorax, and abdomen. This paper is intended to allow further comparative contributions regarding the Neotropical lycaenid butterflies. Hemiargus hanno (Stoll, 1790) is chosen as first Neotropical polyommatine to be described in detail. This butterfly is a common species in many open weedy areas, pastures, and fields, widely distributed from southern Texas and Central America to Argentina. Line drawings and SEM photographs are provided.
\end{abstract}

KEYWORDS. Papilionoidea, Lycaenidae, Hemiargus, morphology, Downey's area.

RESUMO. O presente trabalho visa fornecer subsídios para estudos morfológicos comparativos de Lycaenidae neotropicais. Hemiargus hanno (Stoll, 1790) é a primeira espécie neotropical de Polyommatinae a ter sua morfologia detalhada na literatura. Essa borboleta pode ser encontrada em ambientes abertos com vegetação rasteira, desde o sul do Texas até a Argentina. A morfologia da região cervical, do tórax e do abdome de $H$. hanno foi estudada com auxílio da microscopia óptica e de varredura.

PALAVRAS-CHAVE. Papilionoidea, Lycaenidae, Hemiargus, morfologia, área de Downey.

Lycaenidae se destaca por possuir uma das maiores riquezas de espécies dentro da superfamília Papilionoidea, agregando pouco mais de um terço da fauna neotropical (ACKERY et al., 1998; Brown \& FreITAS, 1999). De acordo com algumas estimativas, há em torno de 6.500 espécies de licenídeos em todo o mundo (HEPPNER, 1991; BRIDGES, 1994); destas, quase $40 \%$ ocorrem na Região Neotropical onde, paradoxalmente, poucos taxonomistas estão envolvidos com o grupo (HEPPNER, 1991).

Limitações no conhecimento da família Lycaenidae (i.e., escassez de inventários, de especialistas e de dados sobre imaturos e adultos) têm impedido grandes avanços no entendimento da sistemática e evolução do grupo, assim como de suas interações com outros grupos de insetos (p.ex. mutualismo e parasitismo com formigas e homópteros). Não menos importante também é a falta de consenso que ainda existe com relação à classificação da família (ClenCH, 1955; 1961; 1964; ELIOT, 1973; 1990).

ELIOT (1973), ao propor as bases mais significativas para a classificação superior de Lycaenidae (classificações anteriores em CLENCH, 1955; 1961; 1964), reconheceu oito subfamílias - Lipteninae Röber, 1892; Poritiinae Doherty, 1886; Liphyrinae Doherty, 1889; Miletinae Corbet, 1939; Curetinae Distant, 1884; Theclinae Swainson, 1831; Lycaeninae Leach, 1815 e Polyommatinae Swainson, 1827. Esta classificação foi aos poucos sendo modificada por autores subseqüentes (KRISTENSEN, 1976; ACKerY, 1984). Eliot (1990), ao estudar o gênero Curetis Hübner, 1819, apresentou uma proposta de classificação diferente da publicada em 1973. Ao invés de oito subfamílias, passou a reconhecer apenas cinco Curetinae, Riodininae, Poritiinae (incluindo Lipteninae), Miletinae (incluindo Liphyrinae) e Lycaeninae (incluindo Theclinae, Lycaeninae e Polyommatinae).
Embora vivendo sob o paradigma da Sistemática Filogenética, Eliot $(1973,1990)$ não adotou os procedimentos metodológicos modernos, disponíveis naquela época, para apresentar suas classificações. Mesmo assim, elas continuam sendo adotadas, com pequenas modificações, em vários trabalhos atuais (revisão em BRIDGES, 1994; LAMAS et al., 1995; RoBBins, 2004a,b; RoBBins $\&$ DUARTE, 2004a,b; 2005a,b; 2006). Para os especialistas em Lycaenidae, no entanto, a classificação de 1973 representa melhor a diversidade da família e reúne um número maior de evidências morfológicas (tanto de imaturos quanto de adultos), utilizadas pelo próprio Eцıот (1973) para inferir sobre a história evolutiva dessas borboletas (R. K. Robbins, com. pess.).

Das oito subfamílias reconhecidas por ELIOT (1973), apenas duas - Theclinae (Eumaeini e Theclini) e Polyommatinae (Polyommatini) - possuem representantes na Região Neotropical. Embora com poucas espécies (112 espécies e 54 subespécies sensu Lamas, 2004), os Polyommatinae neotropicais ainda carecem de estudos sistemáticos para o entendimento da origem e evolução da mirmecofilia, muito comum nessa subfamília (FIEDLER, 1991; DuARTe et al., 2001a; Pierce et al., 2002).

No presente trabalho, objetiva-se descrever a morfologia externa da região cervical, do tórax e abdome do adulto de Hemiargus hanno (Stoll, 1790), dando continuidade aos estudos recentes sobre aspectos morfológicos dos Lycaenidae neotropicais (DuARTE et al., 2001a; ROBBINS \& DUARTE, 2005a,b; 2006).

Acrescentam-se ainda algumas comparações com Glaucopsyche lygdamus (Doubleday, 1842), representante da Região Neártica e única espécie de Polyommatinae (Polyommatini) com todos os segmentos do corpo detalhados na literatura até o momento 
(Sorensen, 1980). Além dessa espécie de Polyommatinae, outras de Lycaenidae foram estudadas por NiculEscu (1977, 1981a,b) e Shirôzu \& YАмамото (1956), sem maior aprofundamento.

\section{MATERIAL E MÉTODOS}

Este estudo foi desenvolvido com indivíduos obtidos em laboratório e no campo (DUARTE et al., 2001a, b). Ao todo foram estudados 30 indivíduos (machos e fêmeas). Enfatiza-se a importância das criações para desenvolvimento de estudos morfológicos detalhados, que exigem minuciosas e repetidas dissecações, pois, desta forma, poupam-se os exemplares depositados em coleções científicas.

Segue-se a metodologia empregada por DUARTE $e t$ al. (2001a) no preparo dos exemplares para observação sob microscopia óptica e microscopia eletrônica de varredura. Para a diafanização das asas foram empregados os procedimentos habituais em Lepidoptera (EHRLICH \& EHRLICH, 1961).

Procurou-se seguir a terminologia de SoREnSEN (1980) aplicada a Glaucopsyche lygdamus (Doubleday, 1842), espécie da mesma subfamília e tribo (sensu Eliot, 1973) de H. hanno. Sorensen (1980) discute várias hipóteses de homologia para determinados caracteres dentro de Lepidoptera. Nos casos onde há reconhecida dificuldade em estabelecer homologias e a terminologia não parece ser adequada, segue-se DUARTE et al. (2001b) que por sua vez recorre às contribuições gerais sobre morfologia de insetos (SNODGRASS, 1935; MATSUdA, 1970; 1976).

\section{RESULTADOS}

Região cervical (Figs. 2-4). Região membranosa entre a cabeça e a margem anterior do protórax. Esclerito cervical (cervicalia sensu NicUlescu, 1975) presente, um a cada lado, em forma de "T" deitado (Fig. 4); braços anterior e póstero-dorsal articulados com a cabeça e com o protórax, respectivamente; braço póstero-ventral livre; órgão cervical na superfície póstero-ventral, com microcerdas (Fig. 4). Comprimento do braço anterior variável; braços póstero-dorsal e póstero-ventral subiguais.

Protórax (Figs. 1-5). Pequeno, se comparado ao segmento seguinte, e com o primeiro par de pernas. Noto consistindo de uma placa dorsal (proescutelo sensu Niculescu, 1975) e duas placas laterais (proescuto sensu Niculescu, 1975): aquela subtriangular, conectada à porção dorsal das placas laterais e articulada, posteriormente, com a margem anterior do pré-escuto II (Figs. 1, 3, 5); placas laterais unidas medianamente, dando origem ao apódema pronotal (apódema dorsal sensu EHRLICH, 1960), lateralmente conectadas à pleura por intermédio da articulação pronoto-pleural (Figs. 3, 5). Patágio pouco esclerotizado, ligado à margem anterior da placa dorsal (Figs. 1, 3). Parapatágio ausente.

Pleura representada látero-externamente pelo episterno I, maior esclerito da pleura; epimero I não identificado; sutura pleural evidente, contígua à margem posterior do episterno I, ligando os pontos de articulação pronoto-pleural e pleural da coxa (Fig. 3) e, internamente, produzindo a lamela pleural (lamela furcal sensu EHRLICH, 1958a), unida à furca.

Basisterno I mais largo que longo (Fig. 2), medianamente marcado pelo discrime I (sutura longitudinal mediana I sensu Sorensen, 1980) que dá origem à lamela esternal I, a qual se estende entre as coxas até o furcasterno I. Este, externamente, formando a margem posterior do alvéolo coxal I e, na região central, alojando a fóvea furcal subpentagonal (Fig. 2). Espinasterno I constituído de uma parte alongada, articulada com a margem posterior do furcasterno, e outra (mesoclidium sensu NiculEscu, 1975) subtriangular, livre, nunca fusionada ou articulada ao esternopleurito II (ver discussão em SNODGRASS, 1935:167); internamente formando a espina (Figs. 2, 3), considerada como um processo apodemal (SNODGRASS, 1935).

Mesotórax (Figs. 1, 2, 6-8). Maior segmento torácico, com o primeiro par de asas e o segundo par de pernas. Pré-escuto II triangular, pequeno, anteriormente articulado com a placa dorsal do pronoto e, posteriormente, com o escuto II, do qual se separa por meio da sutura pré-escuto-escutal (MATSUDA, 1970). Processo pré-alar tocando a margem anterior da subtégula. Escuto II convexo em vista lateral, com linha mesoescutal estendendo-se do pré-escuto II até próximo da sutura escuto-escutelar II. Três processos notais suportam pontos de articulação com a asa anterior: processo notal anterior II, formado pela suralar II; processo notal mediano II, após a incisão escutal, na extremidade do adnotal II; processo notal posterior II, na extremidade da placa pós-alar II (EhrLich, 1958a; Casagrande, 1979; Bilotta, 1995). Processos notais anterior e mediano associados ao primeiro esclerito axilar, e o posterior ao quarto esclerito axilar (ver adiante "escleritos axilares", Figs. 15-18). Tégula localizada na porção ântero-dorsal do escuto, convexa em sua porção anterior, com o processo dorsal alongado distalmente e o ventral passando por baixo da base da asa anterior. Escutelo II subquadrangular, separado do escuto II pela sutura escuto-escutelar II; margem ântero-lateral contígua à corda axilar II; margem póstero-lateral projetada ventralmente, conectando-se ao pós-noto II. Este, entre o mesotórax e o metatórax, sob a margem posterior do escutelo II (SNODGRASs, 1935; MATSUDA, 1970; SORENSEN, 1980), produzindo látero-ventralmente a ponte pós-alar ("mesopons" sensu Niculescu, 1975), ou simplesmente pós-alar (porção pós-alar do epimero sensu Ehrlich, 1958a; CASAGRANDE, 1979; BilotTa, 1995), em contato com a margem posterior do escutelo, próximo à base da corda axilar II, e com o processo notal posterior II, onde se invagina para formar pontos de inserção muscular (laterophragma/laterophragmata sensu Sorensen, 1980). Fragma II (segundo fragma sensu SNODGRASS, 1935) com depressão mediana na margem póstero-ventral (Figs. 7, 8).

Pleura dividida pela sutura pleural em uma porção anterior, episterno II, e outra posterior, epimero II. Episterno II simples; fenda anapleural e anepisterno II não visíveis. Catepisterno II (infraepisterno sensu SoRENSEn, 1980) e pré-episterno II fusionados, láteroventralmente produzidos até o discrime II, formando uma 

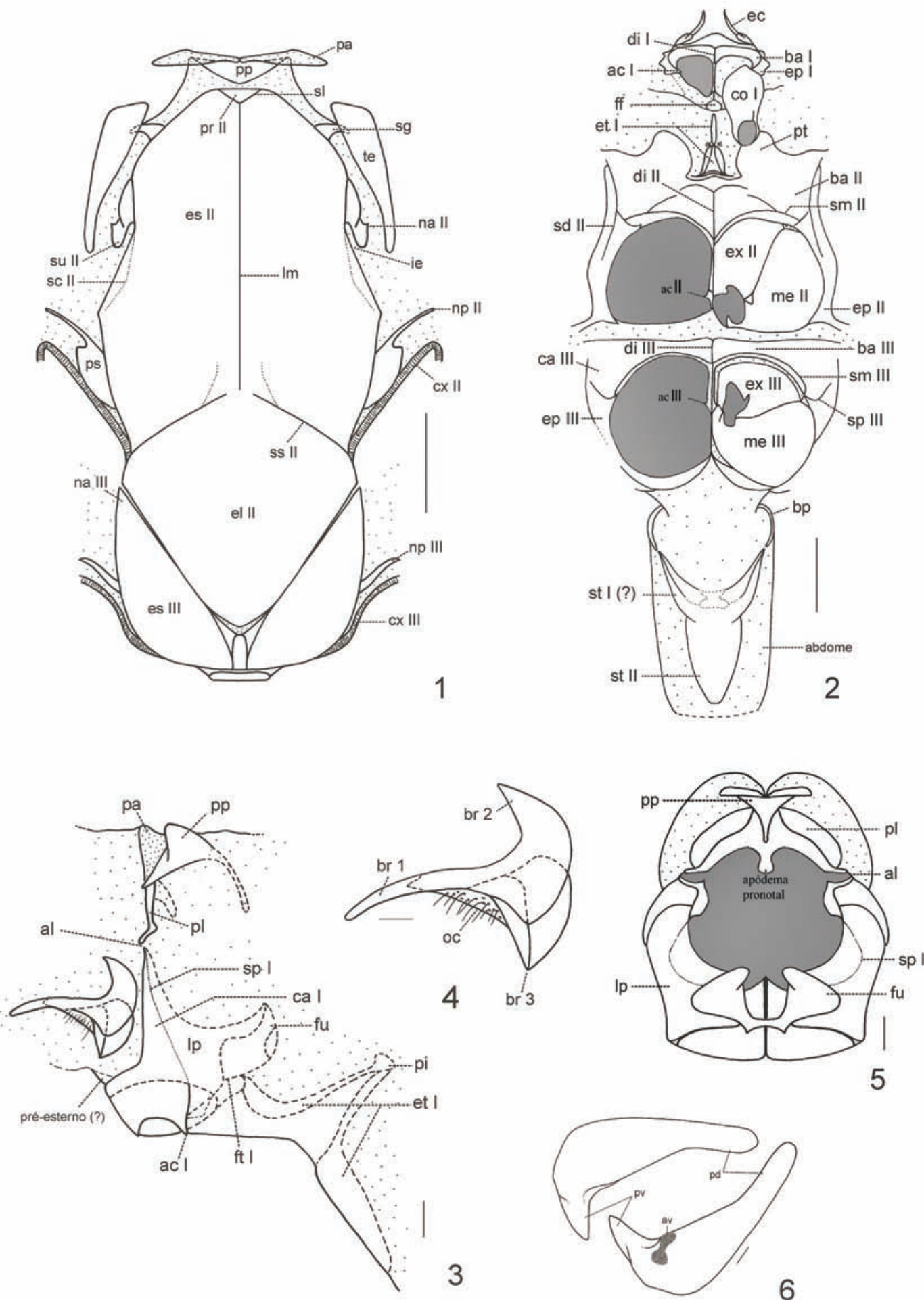

5

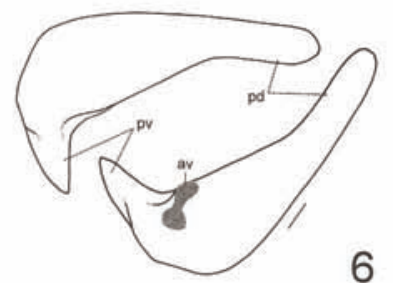

Figs. 1-6. Hemiargus hanno (Stoll, 1790). 1, tórax, vista dorsal. 2, tórax e abdome (parcial), vista ventral. 3, protórax, vista lateral. 4, esclerito cervical, vista lateral. 5, protórax, vista posterior. 6, tégula, vistas externa e interna. (ac I, articulação da coxa I; ac II, articulação da coxa II; ac III, articulação da coxa III; al, articulação pronoto-pleural; av, alvéolo; ba I, basisterno I; ba II, basisterno II; ba III, basisterno III; bp, barra pré-espiracular; br 1, braço anterior; br 2, braço póstero-dorsal; br 3, braço póstero-ventral; ca I, catepisterno I; ca III, catepisterno III; co I, coxa I; cx II, corda axilar II; cx III, corda axilar III; di I, discrime I; di II, discrime II; di III, discrime III; ec, esclerito cervical; el II, escutelo II; ep I, epimero I; ep II, epimero II; ep III, epimero III; es II, escuto II; es III, escuto III; et I, espinasterno I; ex II, eucoxa II; ex III, eucoxa III; ff, fóvea furcal; ft I, furcasterno I; fu, furca; ie, incisão escutal; lm, linha mesoescutal; lp, lamela pleural; me II, mero II; me III, mero III; na II, processo notal anterior II; na III, processo notal anterior III; np II, processo notal posterior II; np III, processo notal posterior III; oc, órgão cervical; pa, patágio; pd, processo dorsal; pi, espina; pl, placa lateral do pronoto; pp, placa dorsal do pronoto; pr II, pré-escuto II; ps, placa pós-alar; pt, prepecto; pv, processo ventral; sc II, sutura escutal II; sd II, sutura epimerodorsal II; sg, subtégula; sl, sutura pré-escuto escutal; sm II, sutura marginopleural II; sm III, sutura marginopleural III; sp I, sutura pleural I; sp III, sutura pleural III; ss II, sutura escuto-escutelar II; st I, esterno I; st II, esterno II; su II, suralar II; te, tégula). Escalas, figs. 1, 2, 6: 0,5 mm; 3, 4, 5: 1,0 mm. 
placa única com o basisterno II (placa "infraepisternalbasisternal" sensu Sorensen, 1980) e ventralmente delimitada pela sutura marginopleural II; esta lateralmente contínua à sutura pleural. Prepecto presente ("peristernum" sensu Niculescu, 1975; pré-episterno sensu MAdDen, 1944; Michener, 1952; Ehrlich, 1958a; CASAgrande, 1979; BilotTA, 1995), com esclerotização secundária (SNOdGRASs, 1935; MATSUdA, 1970; SoRENSEN, 1980). Sutura esternopleural (sutura pré-coxal sensu EhrLICH, 1958a; CASAGRANDE, 1979; BILOTTA, 1995; sutura marginopleural 2 sensu EHRLICH, 1960; sutura paracoxal sensu MATSUDA, 1970) perpendicular ao sexto inferior da sutura pleural (Fig. 7). Epimero II tão largo quanto longo, dorsalmente preenchido por uma região membranosa onde estão os epipleuritos basalar II e subalar II; aquele pequeno, articulando-se com o processo alar mesopleural, o outro, bem distinto, oblongo, pósterodorsalmente unido à ponte pós-alar, com uma fenda transversal; pré-epimero, delimitado pelas suturas pleural, epimerodorsal e pré-epimeral (Fig. 7). Sutura epimeroventral II perpendicular à margem posterior do epimero (Figs. 7, 8). Espiráculo mesotorácico anterior ao pré-alar, na membrana intersegmentar do pro- e mesotórax.

Esterno com os mesmos elementos estruturais do prosterno, variando a forma e/ou tamanho destes elementos. Basisterno II formando o discrime II e a lamela
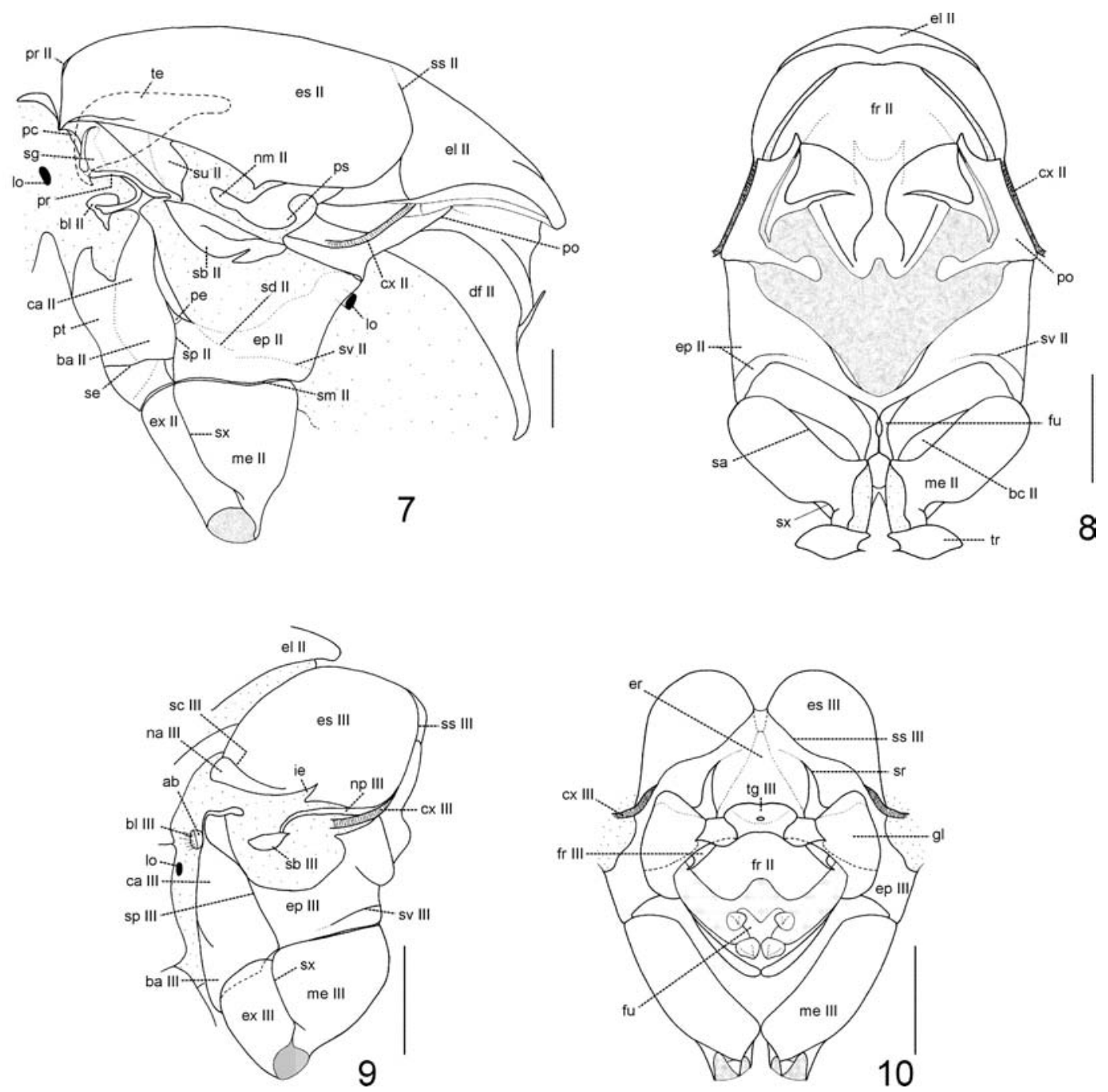

Figs. 7-10. Hemiargus hanno (Stoll, 1790). Mesotórax: 7, vista lateral; 8, vista posterior. Metatórax: 9, vista lateral; 10, vista posterior. (ab, "almofada" da basalar III; ba II, basisterno II; ba III, basisterno III; bc II, basicosta II; bl II, basalar II; bl III, basalar III; ca II, catepisterno II; ca III, catepisterno III; cx II, corda axilar II; cx III, corda axilar III; df II, diafragma II; el II, escutelo II; ep II, epimero II; ep III, epimero III; er, esclerito escutelar secundário; es II, escuto II; es III, escuto III; ex II, eucoxa II; ex III, eucoxa III; fr II, fragma II; fr III, fragma III; fu, furca; gl, esclerito suprafragmal; ie, incisão escutal; lo, espiráculo; me II, mero II; me III, mero III; na III, processo notal anterior II; nm II, processo notal mediano II; np III, processo notal posterior III; pc, processo da pré-alar; pe, pré-epimero; po, ponte pós-alar; pr II, pré-escuto II; pr, pré-alar; ps, pós-alar II; pt, prepecto; sa, sutura basicostal; sb II, subalar II; sb III, subalar III; sc III, sutura escutal III; sd II, sutura epimerodorsal II; se, sutura esternopleural; sg, subtégula; sm II, sutura marginopleural II; sp II, sutura pleural II; sp III, sutura pleural III; sr, sutura escutelar secundária; ss II, sutura escuto-escutelar II; ss III, sutura escuto-escutelar III; su II, suralar II; sv II, sutura epimeroventral II; sv III, sutura epimeroventral III; sx, sutura coxal; te, tégula; tg III, transfragma III; tr, trocanter). Escalas, 0,5 $\mathrm{mm}$. 
esternal II; esta, curvada posteriormente, sub-retangular, margem dorsal retilínea, fusionada à base da furca II, originando a articulação ventral da coxa II. Furcasterno II representado internamente pela furca II, ramificada, formando o braço secundário da furca.

Metatórax (Figs. 1, 2, 9, 10) com o segundo par de asas e o terceiro par de pernas. Escuto III consistindo de duas placas contíguas ao escutelo II, subtriangulares em vista dorsal (Figs. 1, 7). Dois processos notais: anterior III, na extremidade do suralar III (sutura escutal ânterolateral sensu MATSUDA, 1970) e posterior III, após a incisão escutal; processo notal mediano aparentemente ausente. Escutelo III póstero-dorsal, entre as placas do escuto III, separando-se deste pela sutura escuto-escutelar III e lateralmente dando suporte à corda axilar III (Figs. 9, 10); esta, terminando na base da asa posterior. Esclerito suprafragmal entre a margem posterior do escutelo e a margem anterior do pós-noto; transfragma III, elíptico, entre as projeções do fragma III (Fig. 10).

Pleura semelhante ao do segmento anterior. Anepisterno III dorsal ao catepisterno III, separado deste por meio da sutura anapleural, ântero-dorsalmente articulando-se com a margem posterior do epipleurito basalar III, localizado na "almofada" do basalar III (SHEPARD, 1930) (anepisterno sensu EHRLICH, 1958a) e representada por um saco membranoso, pequeno, ovalado, com cerdas orientadas caudalmente, e de possível função sensorial (SorEnsen, 1980). Sutura esternopleural ausente. Sutura marginopleural III ao longo da margem ventral do esclerito formado pelo catepisterno III e basisterno III, entre a sutura pleural III e o discrime III. Pré-epimero, suturas pré-epimeral e epimerodorsal ausentes. Sutura epimeroventral III retilínea. Subalar III com um apódema subalar, espatulado e pequeno. Espiráculo mesotorácico junto à margem posterior do epimero III, na membrana intersegmentar do meso- e metatórax (Figs. 7, 9).

Esterno semelhante ao do segmento anterior, proporcionalmente menor. Furca com braços secundários fusionados, em forma de "V" (Fig. 10).

Asa anterior (Figs. 11, 13). Subtriangular; ápice não projetado. Comprimento (base até término da veia $\mathrm{R}_{4+5}$ ) $10,44 \mathrm{~mm}$ no macho (desvio-padrão $=1,12 ; \mathrm{n}=10$ ); 9,98 mm na fêmea (desvio-padrão $=0,58 ; n=8$ ). Margem externa reta no macho, ligeiramente curva na fêmea. Ângulo anal obtuso. Subcosta $(\mathrm{Sc})$ terminando na margem costal e sem exceder a célula discal. Rádio ( $\mathrm{R}$ ) bifurcado além do início da metade distal em $\mathrm{R}_{1}$ e no setor radial ( $\mathrm{Rs}$ ), constituído pelas veias $R_{2}, R_{3}$ e $R_{4+5}$. $R_{1}$ com a porção basal sinuosa, quase fusionada à veia Sc na fêmea (Fig. 13). $R_{2}$ mais próxima da ramificação $R_{3}$ e $R_{4+5}$ do que de $R_{1}$. $\mathrm{R}_{3}$ terminando antes do ápice e $\mathrm{R}_{4+5}$ mais próxima do ápice. Média (M) com as veias $\mathrm{M}_{1}, \mathrm{M}_{2}$ e $\mathrm{M}_{3}$ paralelas entre si até a margem externa; $\mathrm{M}_{2}$ eqüidistante de $\mathrm{M}_{1}$ e $\mathrm{M}_{3}$, tanto no macho quanto na fêmea. Cúbito anterior $(\mathrm{CuA})$ próximo da porção mediana da célula discal, ramifica-se nas cubitais $\mathrm{CuA}_{1}$ e $\mathrm{CuA}_{2}$, paralelas até a margem externa. Duas veias anais: $2 \mathrm{~A}$, paralela à margem interna; $3 \mathrm{~A}$ oblíqua e pouco desenvolvida. Célula discal limitada pelas bases do rádio e do cúbito anterior, fechada em sua porção
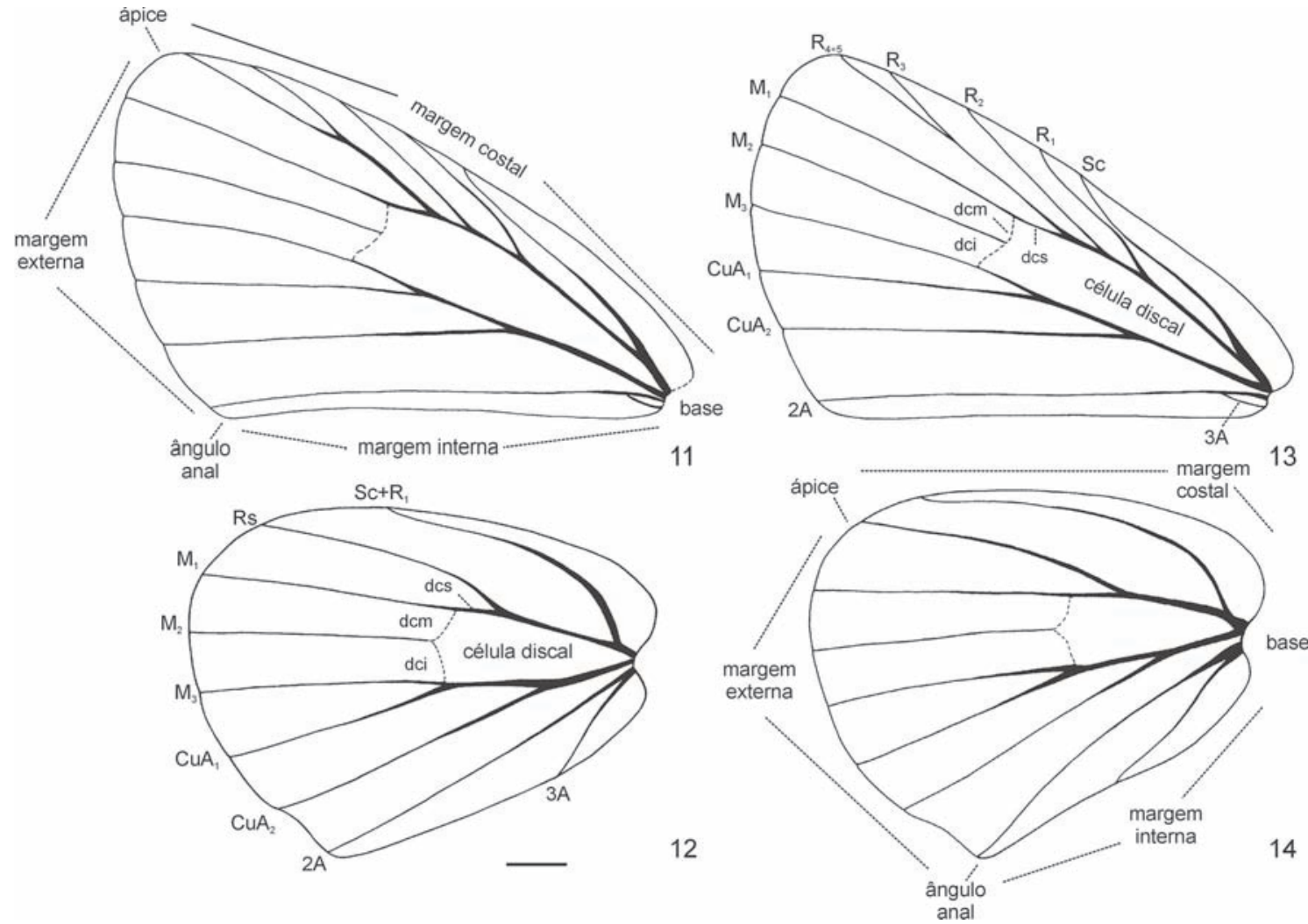

Figs. 11-14. Hemiargus hanno (Stoll, 1790). Asa, macho: 11, anterior; 12, posterior. Asa, fêmea: 13, anterior; 14, posterior. (dcs, discocelular superior; dcm, discocelular média; dci, discocecular inferior). Escala, 1,0 mm. 
distal pelas veias transversais des (discocelular superior), dcm (discocelular média) e dci (discocelular inferior).

Asa posterior (Figs. 12, 14). Difere da asa anterior pelo número reduzido de veias e formato arredondado. Ligeiramente mais alongada na fêmea do que no macho. Subcosta, rádio e cúbito anterior unidos na base. $\mathrm{Na}$ fêmea, $\mathrm{Sc}+\mathrm{R}_{1}$ terminando mais próximo do ápice. Setor radial (Rs) terminando na extremidade. $M_{1}, M_{2}$ e $M_{3}$ paralelas entre si até a margem externa. Cúbito anterior ramificado em $\mathrm{CuA}_{1}$ e $\mathrm{CuA}_{2}$. Duas anais, $2 \mathrm{~A}$ e $3 \mathrm{~A}$, a primeira terminando no lóbulo anal, a outra, mais curta e sigmóide, terminando na margem interna.

Escleritos axilares (Figs. 15-18). (1) Asa anterior (Figs. 15, 16): primeiro axilar de formato irregular, visível apenas dorsalmente; comunica-se ântero-basalmente com o processo basal da subcosta e com a suralar II, ânterodistalmente com o segundo axilar, e posteriormente com o processo notal mediano II. Segundo axilar composto de uma unidade dorsal e outra ventral; dorsalmente disposto entre a placa radial e o primeiro axilar, ventralmente comunicando-se com a primeira placa mediana, com a subalar e com o processo pleural da asa anterior. Terceiro axilar fusionado com a primeira placa mediana e em contato com as veias anais; posteriormente articulando-se com o prolongamento do processo notal posterior II. Placa mediana II pouco esclerotizada, posicionada entre as veias $\mathrm{R}$ e $2 \mathrm{~A}$ e em contato com a placa mediana I. (2) Asa posterior (Figs. 17, 18): primeiro axilar alongado, posicionado longitudinalmente à margem lateral do escuto; distalmente articulado com o segundo axilar e, ântero-distalmente, com o processo ventral do cúbito. Processo ventral $\mathrm{Sc}+\mathrm{R}$ presente na base do tronco que dá origem às veias $\mathrm{Sc}+\mathrm{R}$ e Rs. Não existe uma placa radial homóloga àquela encontrada na asa anterior.

Perna protorácica (Figs. 19, 20, 25-27, 29, 30). Coxa alongada, cilíndrica, mais larga na base do que na porção distal; margem proximal circundada pela sutura basicostal, internamente formando a basicosta (Fig. 19); articulação monocondílica com a propleura; sutura coxal descontínua próximo à base (Figs. 19, 20). Trocanter pequeno, cerca de um terço do maior comprimento da coxa; articulação dicondílica com a coxa. Fêmur inerme, maior artículo no macho cerca de cinco vezes o comprimento do trocânter e três vezes e meia na fêmea. Tíbia inerme; extremidade proximal pouco mais estreita; processo aculeado na extremidade distal (Figs. 25, 26); um par de espinhos tibiais; articulação dicondílica com o fêmur. Tarso com dimorfismo sexual. Macho com um único tarsômero, tão longo quanto a tíbia; garras tarsais ausentes (Figs. 25, 27); espinhos posteriores ordenados em fileiras laterais, unidas distalmente. Fêmea com cinco tarsômeros (Fig. 20); comprimento do basitarso igual ou maior que a soma dos demais tarsômeros; tarsômeros medianos subiguais;
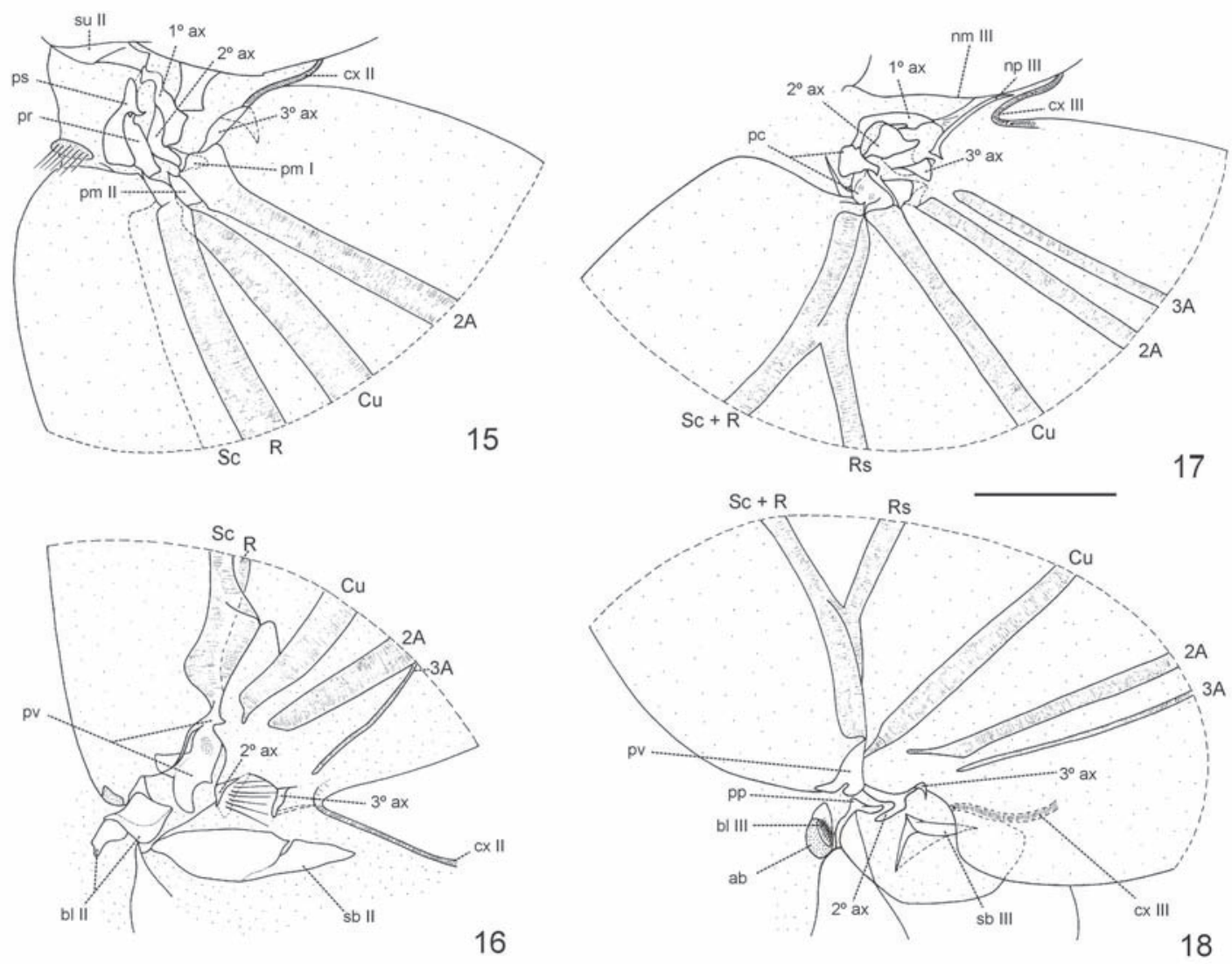

Figs. 15-18. Hemiargus hanno (Stoll, 1790). Escleritos axilares, asa anterior: 15, vista dorsal; 16, vista látero-ventral. Escleritos axilares, asa posterior: 17 , vista dorsal; 18 , vista látero-ventral. ( $1^{\circ} \mathrm{ax}$, primeiro esclerito axilar; $2^{\circ}$ ax, segundo esclerito axilar; $3^{\circ}$ ax, terceiro esclerito axilar; ab, "almofada" da basalar III; bl II, basalar II; bl III, basalar III; cx II, corda axilar II; cx III, corda axilar III; nm III, processo notal mediano III; np III, processo notal posterior III; pc, processo basal do cúbito; pm I, placa mediana I; pm II, placa mediana II; pp, processo pleural; pr, placa radial; ps, processo basal da subcosta; pv, processo ventral Sc + R; sb II, subalar II; sb III, subalar III; su II, suralar II). Escala, $0,5 \mathrm{~mm}$. 
distitarso pouco maior, com longas cerdas na porção distal; pretarso distinto; garras tarsais simples e simétricas; placa unguitratora escamiforme (Figs. 23, 24, 29, 30), disposta entre os pulvilos bilobados (Figs. 23, 24, 28); câmara estreita, anelar, na porção distal do tarso, sustentando o arólio (Fig. 23, 24, 28).

Perna mesotorácica (Fig. 21). Monomorfa, semelhante à perna protorácica da fêmea, proporcionalmente maior, diferindo ainda pelos seguintes caracteres: sutura coxal bem desenvolvida, dividindo a coxa em dois escleritos, um anterior, a eucoxa, outro posterior, o mero (Fig. 21); esporões tibiais robustos.

Perna metatorácica (Figs. 22, 28). Semelhante à perna mesotorácica, porém a eucoxa é mais larga (Fig. 22).

Abdome (Figs. 31-43). Dez segmentos em ambos os sexos, apenas oito visíveis. Modificações aparentes no primeiro e segundo segmentos para articulação com o metatórax; no oitavo esterno, nono e décimo segmentos da fêmea e no nono e décimo segmentos do macho para formação das respectivas genitálias (Figs. 37-43). Tergo I

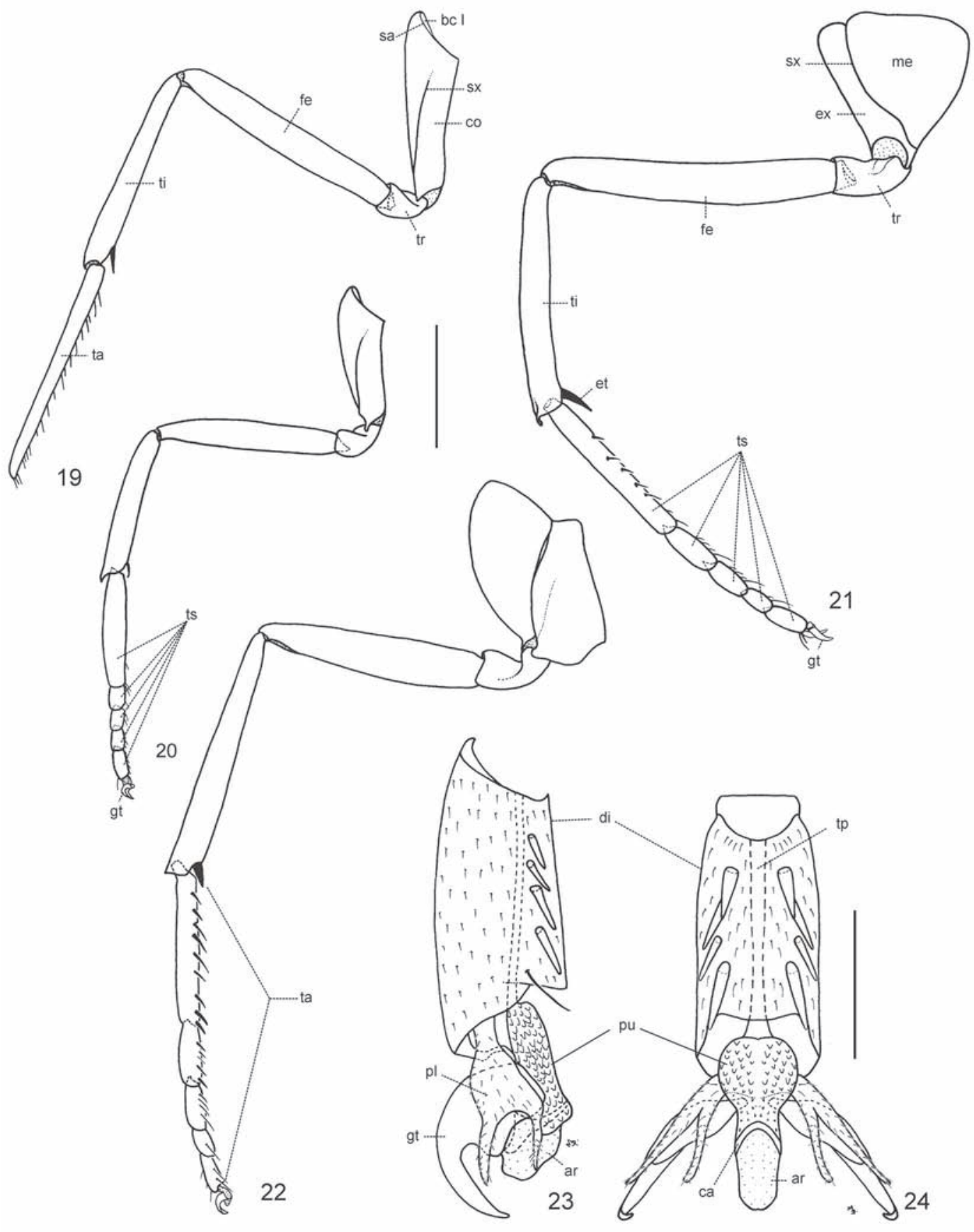

Figs. 19-24. Hemiargus hanno (Stoll, 1790). Perna protorácica: 19, macho; 20, fêmea. 21, perna mesotorácica. 22, perna metatorácica. Distitarso: 23, vista lateral externa; 24, vista ventral. (ar, arólio; bc I, basicosta I; ca, câmara; co, coxa; di, distitarso; et, esporão tibial; ex, eucoxa; fe, fêmur; gt, garra tarsal; me, mero; pl, pulvilo; pu, placa ungüitratora; sa, sutura basicostal; sx, sutura coxal; ta, tarso; ti, tíbia; tp, tendão da placa ungüitratora; tr, trocanter; ts, tarsômeros). Escalas, $0,5 \mathrm{~mm}$. 
muito reduzido em relação ao tergo II; a metade anterior membranosa, a posterior proeminente e projetada sobre o tergo II; na fêmea, menos proeminente. Barra tergopleural mais desenvolvida na fêmea, quase tocando o esterno I, unida póstero-ventralmente à barra pósespiracular (tergo II) e anteriormente à barra préespiracular (esterno I) através do lóbulo tergal. Macho com uma mancha elíptica reticulada, de textura mosaica e função desconhecida, denominada área de Downey (sensu Sorensen, 1980) (Figs. 31, 33-36); em alguns exemplares, pouco nítida, talvez em função do grau de esclerotização do tegumento ou do tempo de ação do hidróxido de potássio.

Genitália masculina (Figs. 37-42). Dividida em duas partes (PIERCE, 1909; 1914): a externa constituída por tegume, unco, gnato e valvas; a interna representada pelo pênis, formado pelo bulbo ejaculatório, edeago e vesica (OітісісA Filho, 1946). Tegume subtriangular em vista lateral, comunica-se ao unco por intermédio de um prolongamento posterior, e ventralmente pelo braço do tegume ao saco reduzido (BAKER, 1891); unco bífido, em vista dorsal, com dois lóbulos pilosos, alongados e
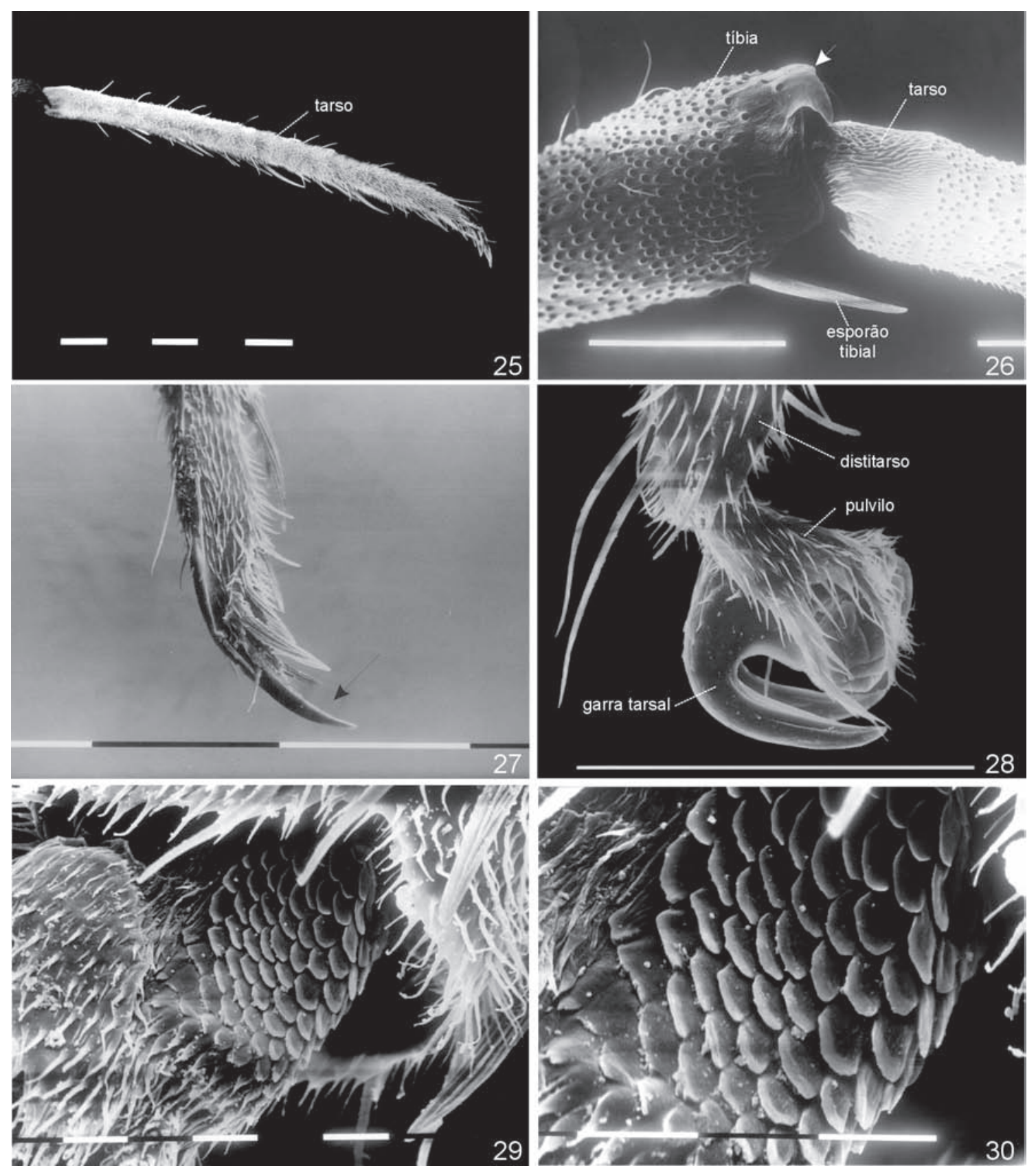

Figs. 25-30. Hemiargus hanno (Stoll, 1790). 25, tarso (perna protorácica), macho. 26, articulação tíbia+tarso (perna protorácica), macho (seta indicando processo aculeado na extremidade distal da tíbia). 27, porção distal do tarso (perna protorácica), macho (seta indicando um processo esclerotizado). 28, parte do distitarso, perna metatorácica, macho, vista lateral externa. 29, parte do distitarso, placa ungüitratora, perna protorácica, fêmea. 30, detalhe das "escamas" da placa ungüitratora, perna protorácica, fêmea. Escalas, figs. 25-28: cada graduação branca na escala corresponde a $0,1 \mathrm{~mm}$; figs. 29-30: cada graduação branca na escala corresponde a $10 \mu$ m. 

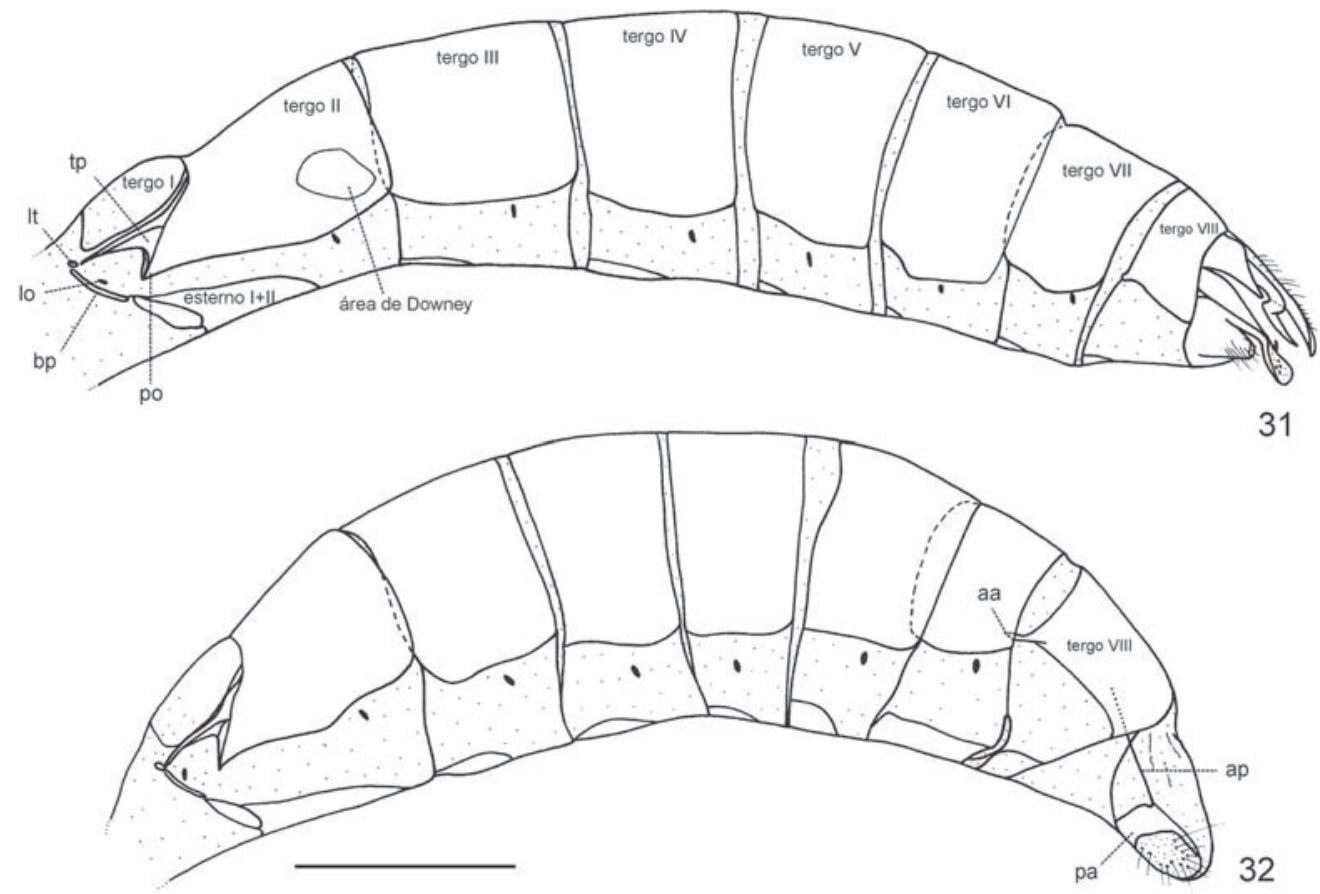

Figs. 31-32. Hemiargus hanno (Stoll, 1790). Abdome, vista lateral: 31, macho; 32, fêmea. (aa, apófise anterior; ap, apófise posterior; bp, barra pré-espiracular; lo, espiráculo; lt, lóbulo tergal; pa, papila anal; po, barra pós-espiracular; tp, barra tergo-pleural). Escala, $0,5 \mathrm{~mm}$.
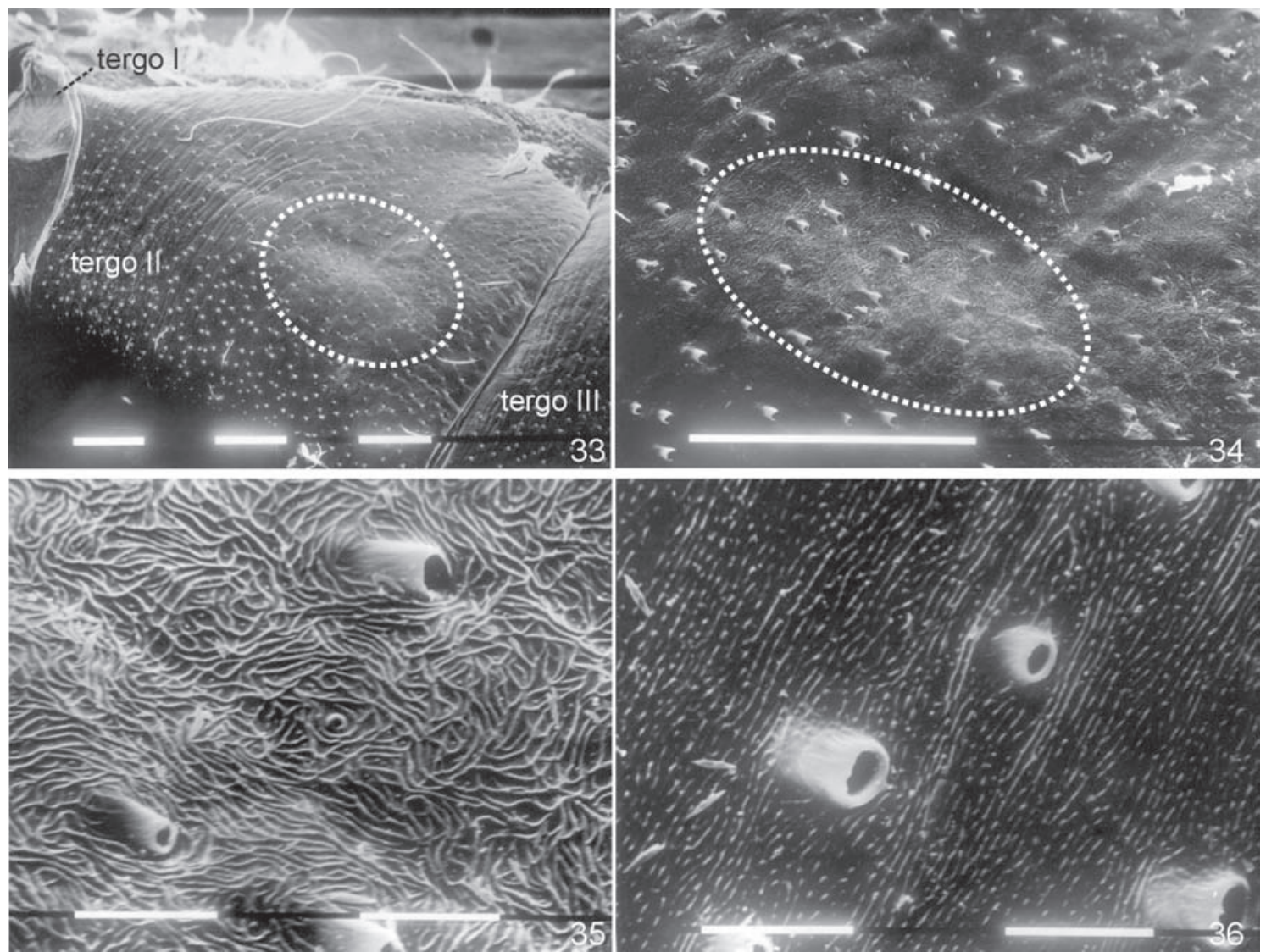

Figs. 33-36. Hemiargus hanno (Stoll, 1790). 33, abdome parcial, macho; no destaque, a área de Downey. 34, detalhe da área de Downey. 35, diferenciação do tegumento na área de Downey. 36, tegumento fora da área de Downey. Escalas, figs. 33-34: cada graduação branca na escala corresponde a 0,1 mm; figs. 35-36: cada graduação branca na escala corresponde a $10 \mu \mathrm{m}$. 
distalmente afilados, separados por uma profunda depressão. Saco sem prolongamento anterior. Valva subtriangular, bilobada no terço posterior, ânterolateralmente articulada com o braço do tegume, ligeiramente menor que o edeago; lóbulo ventral piloso, curto e arredondado, o outro, glabro e dorsal, com poucas cerdas internamente, mais longo e encurvado ventralmente no terço apical, terminando em um processo pontiagudo não-denteado que NABokov (1945) chamou de rostelo. Gnato projetado em direção caudal, articulando-se com a margem posterior do tegume e a base do unco. Juxta em forma de "V". Parte externa do pênis afilada distalmente, separada da interna pela manica, com um par de processos aculeados na porção distal; parte interna mais robusta com dois prolongamentos láteroproximais (Figs. 41, 42). Bulbo ejaculatório amorfo, com
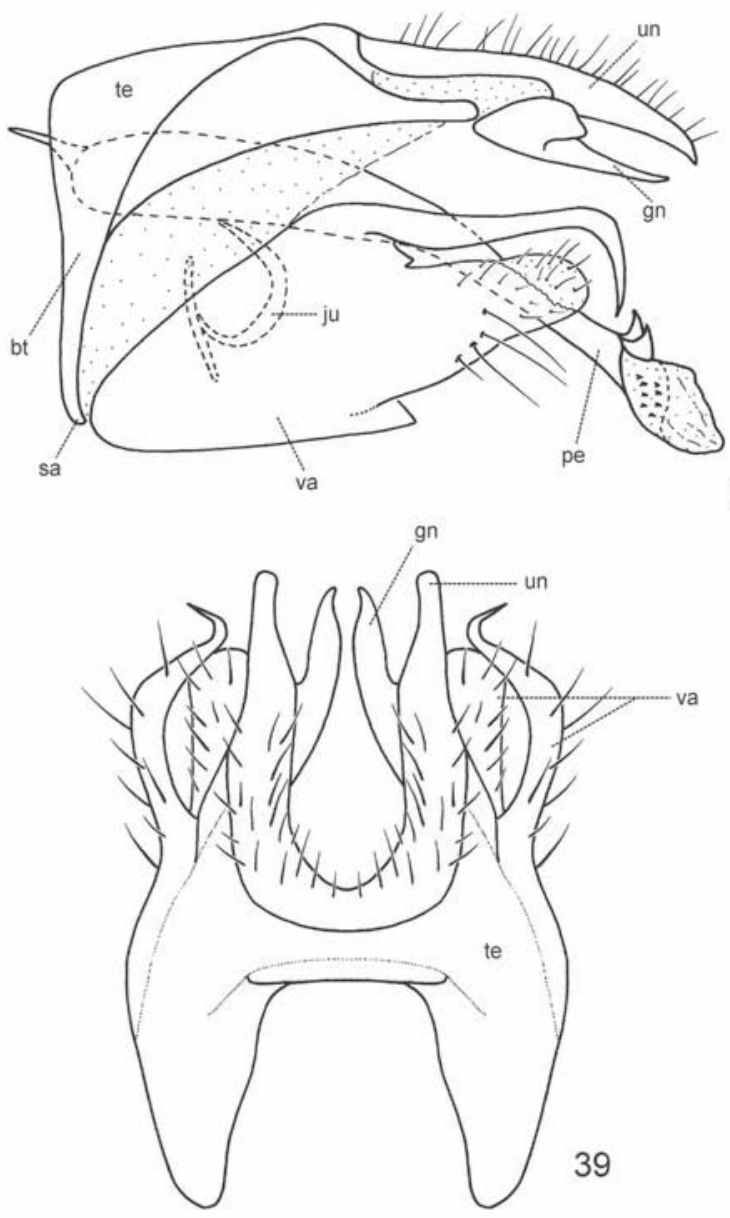

37
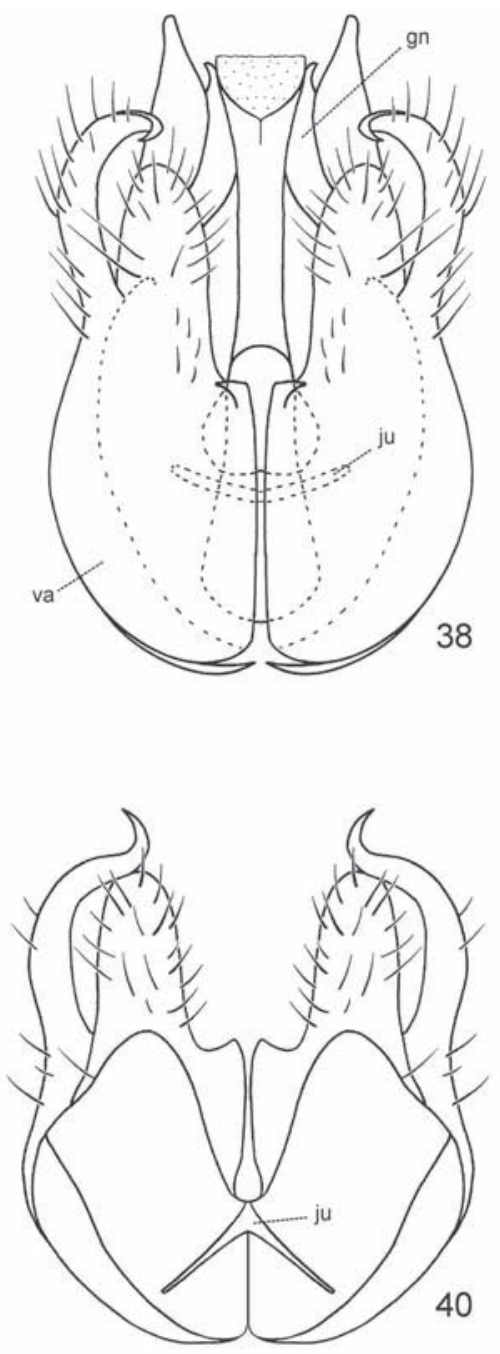

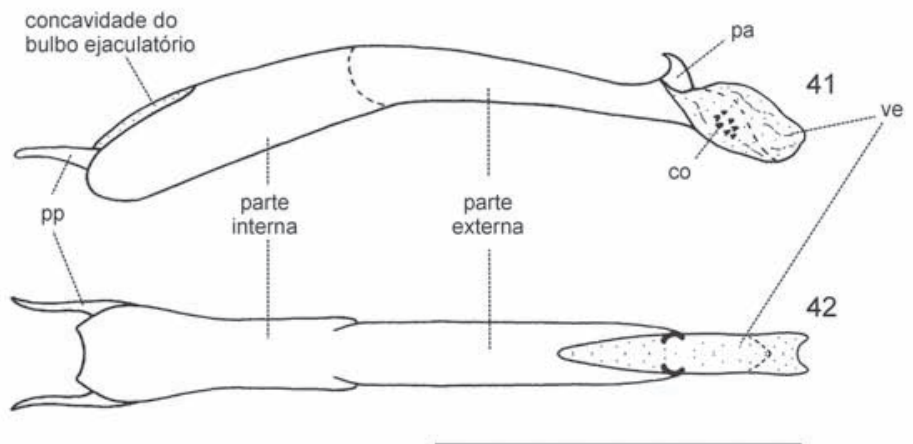

Figs. 37-42. Hemiargus hanno (Stoll, 1790). Genitália masculina: 37, vista lateral; 38, vista ventral; 39, vista dorsal; 40, valvas, vista dorsal. Pênis: 41, vista lateral; 42, vista dorsal. (bt, braço do tegume; co, cornuto; gn, gnato; ju, juxta; pa, processo aculeado; pe, pênis; pp, processo proximal; sa, saco; te, tegume; un, unco; va, valva; ve, vesica). Escala, 0,5 mm. 
origem na concavidade da porção anterior do edeago. Vesica com pequenos cornutos.

Genitália feminina (Fig. 43). Oitavo tergo pouco maior que os anteriores, com apófise anterior reduzida. Apófise posterior projetada anteriormente a partir da papila anal, tão longa quanto esta. Papila anal (tergo IX+X) subretangular, parcialmente membranosa, com inúmeras cerdas apicais. Oitavo esterno com duas placas genitais

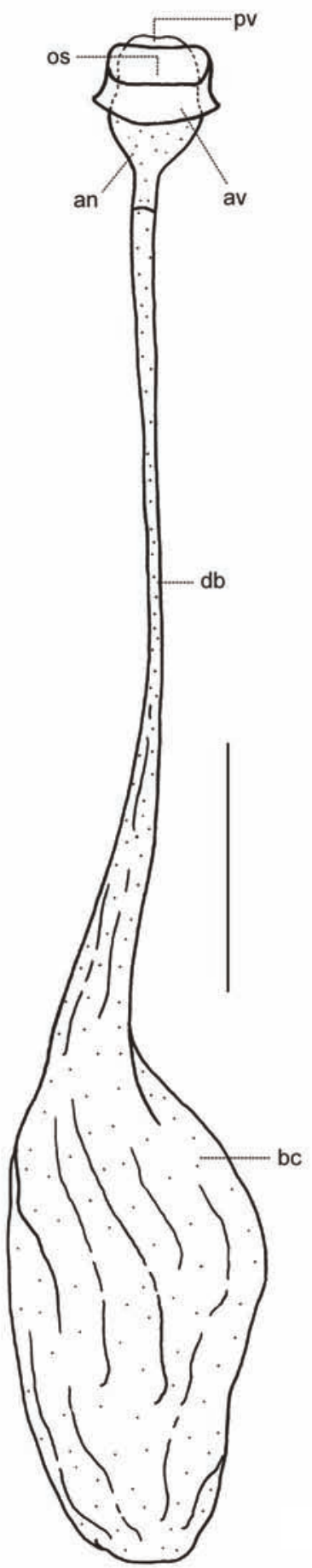

Fig. 43. Hemiargus hanno (Stoll, 1790). Genitália feminina, vista ventral. (an, antro; av, lamela antevaginal; bc, bolsa copuladora; $\mathrm{db}$, duto da bolsa copuladora; os, óstio; pv, lamela pós-vaginal) Escala, $0,5 \mathrm{~mm}$. circundando o óstio da bolsa copuladora, uma anterior, a lamela antevaginal, pouco esclerotizada, e outra posterior, a lamela pós-vaginal, mais esclerotizada, com uma pequena reentrância apical. Duto da bolsa copuladora alongado e membranoso. Corpo da bolsa saculiforme e membranoso. Signos ausentes.

\section{DISCUSSÃO}

Os resultados aqui apresentados complementam o trabalho de DuARTE et al. (2001a) sobre a morfologia externa do adulto de $H$. hanno (Lycaenidae, Polyommatinae, Polyommatini). Estes autores detalharam a morfologia externa da cabeça e de seus apêndices. No presente trabalho, complementa-se a morfologia da espécie com a descrição da região cervical, do tórax e do abdome.

Com relação à região cervical, existem diferentes hipóteses na literatura sobre sua origem. SNODGRASs (1935: 157), por conveniência, a tratou como parte integrante do tórax, mas ressaltou que a região possui elementos estruturais tanto da cabeça quanto do tórax. No estudo com Manduca sexta (Linnaeus, 1764) (Lepidoptera, Sphingidae), MADDEN (1944) considera a região cervical intersegmentar. Finalmente, MATSUDA (1970) concorda com a idéia de Snodgrass e salienta que, de fato, não há evidências embriológicas consistentes para suportar a origem da região cervical a partir de um único segmento ou, ainda, para considerar a região como um segmento independente. Comparando o esclerito cervical de $H$. hanno com a figura apresentada por SoRENSEN (1980:68, fig. 11), percebe-se que o órgão cervical do esclerito cervical de G. lygdamus está localizado na superfície póstero-dorsal, enquanto que em H. hanno e em muitas outras espécies de Lepidoptera, está na porção ventral do esclerito (EHRLICH, 1958a, 1960; Casagrande, 1979; Bilotta, 1995; Bizarro et al., 2003; Mielke et al., 2004; Duarte, dados não-publicados). Provavelmente, SorENSEN (1980) cometeu um equívoco em posicionar o órgão cervical, já que em seu texto ele menciona que o mesmo está na parte póstero-ventral do esclerito, como em H. hanno.

Pouca diferença foi observada entre o protórax de H. hanno e o de G. lygdamus; em vista posterior, o apódema pronotal da primeira espécie é mais curto e robusto, ao contrário da segunda, em que é alongado e estreito. EHRLICH (1958b) ilustrou o apódema pronotal em Phoebis sennae (Linnaeus, 1758) (Pieridae, Coliadinae) e, posteriormente, em Epargyreus clarus (Cramer, 1775) (Hesperiidae, Pyrginae) (EHRlich, 1960). Por outro lado, todos os trabalhos recentes envolvendo espécies neotropicais não descrevem o protórax em vista posterior, o que dificulta nosso entendimento sobre a evolução de determinadas estruturas, como o apódema pronotal.

O meso- e o metatórax de H. hanno e G. lygdamus fornecem bons caracteres, principalmente em vista posterior, conforme já havia sido destacado em trabalhos anteriores com outros grupos de Lepidoptera (EHRLICH, 1958b, 1960; BRock, 1971; Mielke et al., 2004); tais caracteres são merecedores de futuros estudos comparativos. Em H. hanno, o fragma II ocupa apenas uma pequena porção do forame mesotorácico (vista 
posterior, Fig. 8), enquanto que em G. lygdamus a mesma estrutura está bem desenvolvida dorso-ventralmente, ocupando quase todo espaço posterior do mesotórax. O fragma III é muito parecido nas duas espécies, assim como os apêndices torácicos.

A genitália masculina de $H$. hanno já havia sido descrita e ilustrada parcialmente por NABOKOV (1945) e BÁLINT (1993), sendo aqui acrescentadas ilustrações da genitália completa em vistas lateral, ventral e dorsal, além de detalhes internos da valva e do pênis inteiro em vista ventral. Um estudo filogenético de Polyommatinae seria muito importante para determinar a história evolutiva de Hemiargus Hübner, 1818 que, com base no formato da valva, se assemelha aos gêneros Echinargus Nabokov, 1945 e de Chilades Moore, 1881, este do Velho Mundo.

Agradecimentos. Aos Drs. Olaf H. H. Mielke, Universidade Federal do Paraná (UFPR) e Gilson R. P. Moreira, Universidade Federal do Rio Grande do Sul (UFRGS), pelas sugestões e críticas ao manuscrito. À Dra. Daura Regina EirasStofella, Matilde Machado e Vera Regina F. Pionteke, do Centro de Microscopia Eletrônica da UFPR, pela assessoria técnicocientífica. À Fundação de Amparo à Pesquisa do Estado de São Paulo (FAPESP), pela bolsa de Jovem Pesquisador (processo 03/ 05895-4) e pelo auxílio de pesquisa (processo 02/13898-0) para estruturação de um grupo de pesquisa no Museu de Zoologia da Universidade de São Paulo, na área de Sistemática e Evolução de Lepidoptera. À Pró-Reitoria de Pesquisa da Universidade de São Paulo, pelos auxílios financeiros concedidos.

\section{REFERÊNCIAS BIBLIOGRÁFICAS}

ACKERY, P. R. 1984. Systematics and faunistic studies on butterflies. In: Vane-Wright, R. I. \& Ackery, P. R. eds. The biology of butterflies. London, Academic. p.9-21.

Ackery, P. R.; De Jong, R. \& Vane-Wright, R. I. 1998. The butterflies: Hedyloidea, Hesperioidea and Papilionoidea. In: Kristensen, P. N. ed. Lepidoptera, moths and butterflies. 1. Evolution, systematics, and biogeography. Handbook of Zoology 4(35):263-300.

BAKER, G. T. 1891. Notes on the genitalia of a gynandromorphus Eronia hippia. Transactions of the Entomological Society of London 1:1-6.

BÁlint, Z. 1993. A catalogue of polyommatine Lycaenidae (Lepidoptera) of the xeromontane oreal biome in the neotropics as represented in European collections. Reports of the Museum of Natural History, University of Wisconsin 29:1-42.

Bilotta, I. G. 1995. Morfologia comparada do tórax das espécies sulbrasileiras de Morphinae (Lepidoptera, Nymphalidae). Revista Brasileira de Zoologia 11(4):691-713.

Bizarro, J. M. S.; Casagrande, M. M. \& Mielke, O. H. H. 2003. Morfologia externa de Thyridia psidii cetoides (Rosenberg \& Talbot) (Lepidoptera, Nymphalidae, Ithomiinae). II. Tórax e apêndices. Revista Brasileira de Zoologia 20(3):419-425.

Bridges, C. A. 1994. Catalogue of the family-group, genusgroup and species-group names of the Riodinidae and Lycaenidae (Lepidoptera) of the World. Urbana, C. A. Bridges. Paginação não seqüenciada.

BRock, J. P. 1971. A contribution towards an understanding of the morphology and phylogeny of the Ditrysian Lepidoptera. Journal of Natural History 5:29-102.

Brown, K. S., JR. \& Freitas, A. V. L. 1999. Lepidoptera. In: Brandẽo, C. R. F. \& CANCEllo, E. M. eds. Biodiversidade do Estado de São Paulo, Brasil: síntese do conhecimento ao final do século $\mathrm{XX}$, 5: invertebrados terrestres. São Paulo, FAPESP. p.227-243.

Casagrande, M. M. 1979. Sobre Caligo beltrao (Illiger). III: Morfologia externa do adulto - tórax (Lepidoptera, Satyridae, Brassolinae). Revista Brasileira de Biologia 39(2):347-355.
Clench, H. K. 1955. Revised classification of the butterfly family and its allies. Annals of the Carnegie Museum 33(16): 261-274.

1961. Tribe Theclini. In: Ehrlich, P. R. \& Ehrlich, A. H. eds. How to know the butterflies. Dubuque, W. C. Brown. p. $177-220$

1964. A synopsis of the West Indian Lycaenidae, with remarks on their zoogeography. Journal of Research on the Lepidoptera 2(4):247-270.

Duarte, M.; Casagrande, M. M. \& Mielke, O. H. H. $2001 \mathrm{a}$. Morfologia externa do adulto de Hemiargus hanno (Stoll) (Lepidoptera, Lycaenidae, Polyommatinae, Polyommatini). I. Cabeça. Revista Brasileira de Zoologia 18(1):225-238.

Duarte, M.; Almeida, G. L.; Casagrande, M. M. \& Mielke, O. H. H. 2001b. Notes on the last instar and pupa of Hemiargus hanno (Stoll) (Lepidoptera, Lycaenidae, Polyommatinae). Revista Brasileira de Zoologia 18(4):1097-1105.

Ehrlich, P. R. 1958a. The integumental anatomy of the Monarch butterfly Danaus plexippus L. (Lepidoptera: Danaiidae). The University of Kansas Science Bulletin 38(18):1315-1349. 1958b. The comparative morphology, phylogeny and higher classification of the butterflies (Lepidoptera: Papilionoidea) The University of Kansas Science Bulletin 39(8):305-370. 1960. The integumental anatomy of the silver-spotted skipper, Epargyreus clarus Cramer (Lepidoptera: Hesperiidae). Microentomology 24(1):1-23.

Ehrlich, P. R. \& Ehrlich, A. H. 1961. How to know the butterflies. Dubuque, W. C. Brown. 266p.

Eliot, J. N. 1973. The higher classification of the Lycaenidae (Lepidoptera): a tentative arrangement. Bulletin of the British Museum (Natural History) Entomology 28(6):371-505.

1990. Notes on the genus Curetis Hübner (Lepidoptera, Lycaenidae). Tyô to Ga 41(4):201-225.

FiedLer, K. 1991. Systematic, evolutionary, and ecological implications of myrmecophily within Lycaenidae (Insecta: Lepidoptera: Papilionoidea). Bonner Zoologische Monographien 31:1-210.

Heppner, J. B. 1991. Faunal region and the diversity of Lepidoptera. Tropical Lepidoptera 2(suppl.1):1-85.

Kristensen, N. P. 1976. Remarks on the family-level phylogeny of butterflies (Insecta, Lepidoptera, Rhopalocera). Zeitschrift für zoologische Systematik und Evolutions-Forschung 14:25-33.

Lamas, G. 2004. Checklist: Part 4A. Papilionoidea - Hesperioidea. In: Heppner, J. B. ed. Atlas of Neotropical Lepidoptera 5A Gainesville, Scientific Publishers. 439p.

Lamas, G.; Robbins, R. G. \& Field, W. D. 1995. Bibliography of butterflies. An annotated bibliography of the Neotropical butterflies and skippers (Lepidoptera: Papilionoidea and Hesperioidea). In: Heppner, J. B. ed. Atlas of Neotropical Lepidoptera Vol. 124. Gainesville, Scientific Publishers. 463p. Madden, A. H. 1944. The external morphology of the adult tobacco hornworm (Lepidoptera, Sphingidae). Annals of the Entomological Society of America 37(2):145-160.

Matsuda, R. 1970. Morphology and evolution of the insect thorax. Memoirs of the Entomological Society of Canada 76: $1-431$.

1976. Morphology and evolution of the insect abdomen London, Pergamon. 533p.

Michener, C. D. 1952. The Saturniidae (Lepidoptera) of the western hemisphere: morphology, phylogeny, and classification. Bulletin of the American Museum of Natural History 98(5):33-501.

Mielke, C. G. C.; Mielke, O. H. H. \& Casagrande, M. M. 2004. Estudo comparado da morfologia externa de Zaretis itys itylus (Westwood) e Agrias claudina annetta (Gray) (Lepidoptera, Nymphalidae, Charaxinae) II. Tórax e apêndices. Revista Brasileira de Zoologia 21(3):421-433.

NAвокоv, V. 1945. Notes on Neotropical Plebejinae (Lycaenidae, Lepidoptera). Psyche 52 (1-2):1-61.

Niculescu, E. V. 1975. L'exosquelette prothoracique et mesothoracique des Riodinidae (Lepidoptera). Bulletin et Annales de la Société royale entomologique de Belgique 111(4/6):152-162. 
1977. La valeur de quelques caracteres morphologiques dans la systématique de la famille des Lycaenidae (Lepidoptera). Revue Verviétoise d'Histoire Naturelle 34(1-3):2-10.

1981a. Le problème de l'espèce dans la famille des Lycaenidae (Lepidoptera) (I). SHILAP Revista de lepidopterologia 9(34):103-108.

1981b. Le problème de l'espèce dans la famille des Lycaenidae (Lepidoptera) (II). SHILAP Revista de lepidopterologia 9(35):181-186.

Oiticica Filho, J. 1946. Sobre a morfologia do pênis em Lepidoptera. Boletim do Museu Nacional 50:1-36.

Pierce, F. N. 1909. The genitalia of the group Noctuidae of the Lepidoptera of the British Islands. An account of the morphology of the male clasping organs. Liverpool, A. W. Duncan. $88 \mathrm{p}$.

1914. The genitalia of the group Geometridae of the Lepidoptera of the British Islands. An account of the morphology of the male clasping organs and the corresponding organs of the female. Liverpool, A. W. Duncan. 84p.

Pierce, N. E.; Braby, M. F.; Health, A.; Lohman, D. J.; Mathew, J.; Rand, D. B. \& Travassos, M. A. 2002. The ecology and evolution of ant association in the Lycaenidae (Lepidoptera). Annual Review of Entomology 47:733-771.

Robbins, R. K. 2004a. Checklist: Part 4A. Papilionoidea Hesperioidea. In: Heppner, J. B. ed. Atlas of Neotropical Lepidoptera 5A. Gainesville, Scientific Publishers. 439p. 2004b. Checklist: Part 4A. Papilionoidea - Hesperioidea. In: Heppner, J. B. ed. Atlas of Neotropical Lepidoptera 5A. Gainesville, Scientific Publishers. 439p.

Robbins, R. K. \& Duarte, M. 2004a. Checklist: Part 4A.
Papilionoidea - Hesperioidea. In: Heppner, J. B. ed. Atlas of Neotropical Lepidoptera 5A. Gainesville, Scientific Publishers. 439p.

2004b. Checklist: Part 4A. Papilionoidea - Hesperioidea In: Heppner, J. B. ed. Atlas of Neotropical Lepidoptera 5A Gainesville, Scientific Publishers. 439p.

2005a. Two phylogenetically significant new Calycopis species (Lycaenidae: Theclinae: Eumaeini). Journal of Research on the Lepidoptera 38:27-34.

2005b. Phylogenetic analysis of Cyanophrys Clench, a synopsis of its species, and the potentially threatened $C$. bertha (Jones) (Lycaenidae: Theclinae: Eumaeini). Proceedings of the Entomological Society of Washington 107(2):398-416.

2006. Systematic placement of Lycaena cogina Schaus (Lepidoptera: Lycaenidae: Polyommatinae), a biogeographically disjunct New World species. Proceedings of the Entomological Society of Washington 108(1):226236

Shepard, H. H. 1930. The pleural and sternal sclerites of the lepidopterous thorax. Annals of the Entomological Society of America 23:237-260.

Shirôzu, T. \& Yamamoto, H. 1956. A generic revision and the phylogeny of the tribe Theclini (Lepidoptera: Lycaenidae). Sieboldia 1:329-421.

Snodgrass, R. E. 1935. Principles of insect morphology. New York, McGraw Hill. 667p.

SoRENSEN, J. T. 1980. An integumental anatomy for the butterfly Glaucopsyche lygdamus (Lepidoptera: Lycaenidae): a morphological terminology and homology. Zoological Journal of the Linnean Society 70:55-101. 